\title{
Um Estudo da Criação e Desenvolvimento de Licenciaturas em Matemática na Universidade Federal de Mato Grosso do Sul
}

\author{
A Study of the Creation and Development of Undergraduate Mathematics at \\ the Federal University of Mato Grosso do Sul
}

\author{
Marilena Bittar \\ Renato Gomes Nogueira (in memorian) ${ }^{* *}$
}

\begin{abstract}
Resumo
Este texto apresenta um estudo da história da Licenciatura em Matemática, da Universidade Federal de Mato Grosso do Sul (UFMS). Primeiramente, discutimos a criação e posterior federalização da Universidade e o percurso das Licenciaturas em Matemática nos seus diversos campus. Em seguida, analisamos especificamente a Licenciatura em Matemática do Instituto de Matemática, campus de Campo Grande, tendo como fonte as principais mudanças curriculares ocorridas em 30 anos e um levantamento da quantidade de seus egressos nesse período, bem como de sua atuação profissional. Para isso, foram consideradas fontes documentais diversas e respostas de egressos a questionários. Os resultados mostram que é preciso repensar a formação inicial tendo em vista a necessidade de professores para atuarem na Educação Básica.
\end{abstract}

Palavras-chave: Egressos. Licenciatura. Mudanças Curriculares. História da Educação Matemática.

\begin{abstract}
This paper presents a study of the history of the Mathematics major of the Federal University of Mato Grosso do Sul (UFMS). First, we discuss the creation and further federalization of the University and the training course of Mathematics teachers in its various campuses. Secondly, we discuss specifically the Mathematics major of the Institute of Mathematics, located in Campo Grande, having as the main source curricular changes during 30 years time and a survey of the amount of its students in this period, as well as their professional performance. For this, we considered various documentary sources and responses to questionnaires completed by former students. The results show that it is necessary to rethink the initial training in view of the need for teachers to work in basic education.
\end{abstract}

Keywords: Former students; Degree; Curricular changes; History of Mathematics Education

\footnotetext{
* Doutora em Educação Matemática pela Universidade Joseph Fourier, Campo Grande, França. Professora do Instituto de Matemática e Coordenadora do Programa de Pós-Graduação em Educação Matemática da Universidade Federal de Mato Grosso do Sul (UFMS), Campo Grande, Mato Grosso do Sul, Brasil. Líder do DDMat - Grupo de Estudos em Didática da Matemática e Bolsista Produtividade em Pesquisa do CNPq. Endereço para correspondência: Rua Brasil, 86, apartamento 1203, Campo Grande/MS, Brasil, CEP: 79002480,. E-mail: marilenabittar@gmail.com

** Renato Gomes Nogueira faleceu em 2008 quando era professor da Universidade Federal da Grande Dourados (UFGD), em Dourados, Mato Grosso do Sul, Brasil.
} 


\section{Introdução}

Este artigo tem duplo caráter histórico: por um lado discute a história das Licenciaturas em Matemática da Universidade Federal de Mato Grosso do Sul (UFMS) e, por outro, é produzido com base na inserção dos dois autores do texto, ambos egressos de uma dessas Licenciaturas e que se tornaram professores da UFMS com forte atuação na formação de professores de Matemática. Outro aspecto que marca a trajetória acadêmico-profissional dos dois autores é que Renato Gomes Nogueira foi meu ${ }^{1}$ orientando de Doutorado em Educação da UFMS e faleceu em um trágico acidente de carro, poucos dias antes da defesa de sua tese. Ele faz parte da história da Licenciatura em Matemática na UFMS, especialmente por suas posições críticas e preocupações com a educação da população brasileira, e isso desde a época em que era graduando, ocasião em que participou ativamente do movimento estudantil, até seu falecimento precoce, em 2008. A sua postura política e a compreensão que tinha da educação explicam o fato de que a sua tese de Doutorado tenha sido construída com base na seguinte questão: Quais são os saberes matemáticos e como os expressam professores e estagiários no contexto de um trabalho colaborativo de ensino de Matemática no Estágio Supervisionado, num grupo de pesquisa-ação? Tal formulação expressa claramente sua preocupação com a formação inicial e a ação de ser professor, além de outro aspecto que permeou sua vida: o trabalho coletivo como meio de transformação do mundo e o fato de que esse trabalho só é efetivo se é importante e significativo para todos os envolvidos. Parte do texto aqui apresentado foi produzida como estudo para sua tese e outra como fruto da pesquisa intitulada: Um estudo sobre um Curso de Licenciatura em Matemática e seus Egressos ${ }^{2}$. A decisão de refletir e unir essas duas questões foi motivada pela convicção da contribuição científica que tal esforço pode representar e pelo desejo de fazer um tributo a um educador matemático. Dessa forma, presto uma justa homenagem ao amigo, orientando e pesquisador Renato Gomes Nogueira.

Como formadores de professores de Matemática por mais de duas décadas, atuando em disciplinas de conteúdo matemático, como Cálculo, e também naquelas ditas pedagógicas, como Prática de Ensino, o contraste e confronto entre a realidade da Escola Básica, dos licenciandos e de suas Licenciaturas levou-nos, Renato e eu, a tentar compreender tais fenômenos e, ao mesmo

\footnotetext{
${ }^{1} \mathrm{Na}$ redação deste artigo, faço a opção de escrever, ora na primeira pessoa do singular, ora na primeira pessoa do plural com o objetivo de retratar ações/pensamentos individuais ou dos dois autores do artigo.

${ }^{2}$ Pesquisa coordenada pela primeira autora deste artigo, apoiada pelo CNPq.
} 
tempo, a buscar propostas que pudessem aproximar esses dois segmentos da educação: a Escola Básica e o Ensino Superior, mais especificamente, as Licenciaturas. Foi nesse contexto que nasceram os estudos relatados neste texto e no qual são trazidos alguns dados que buscam compreender a Licenciatura em Matemática da UFMS, campus de Campo Grande.

Esta pesquisa tem caráter historiográfico no que diz respeito à reconstituição de um dos aspectos do curso de Matemática da UFMS: sua criação e desenvolvimento. Assim sendo, a metodologia adotada levou em conta procedimentos próprios desse campo de conhecimento, seja quanto às fontes empregadas seja quanto à necessidade de equilíbrio entre dados e teoria, já que o dado deve ser interpretado pelo pesquisador. A esse respeito, Ragazzini (2001), alertando para o risco mais frequente que, historicamente, envolveu a abordagem das fontes pelo pesquisador, a excessiva objetividade, chama a atenção para o atual risco inverso, isto é, o peso demasiado sobre o papel subjetivo do intérprete. Postulando uma posição equilibrada entre objetividade e subjetividade, ele afirma que, por um lado, as fontes não falam por si, são vestígios, testemunhos que respondem às perguntas que lhes são apresentadas e, por outro lado, é somente por meio das fontes que temos acesso ao passado. De acordo com esse autor, devemos evitar dois inconvenientes: 1) não praticar uma historiografia escrava do documento; 2) não praticar uma historiografia sem o rigor com as fontes. Esse cuidado teórico foi importante neste estudo uma vez que, embora os seus autores tenham sido parte da própria história do Curso, aqui não foram tratadas histórias de vida, mas sim a contribuição do conhecimento e da experiência de ambos para a sua interpretação, ou, em outras palavras, para a escrita dessa história.

\section{A Universidade Federal de Mato Grosso do Sul: reestruturação das Licenciaturas}

No antigo estado ${ }^{3}$ de Mato Grosso existia, desde o início da década de 1970, a Universidade Federal de Mato Grosso, com sede na capital Cuiabá. Em decorrência da secular questão separatista no sul e das razões geopolíticas da ditadura militar (1964-1985), o estado foi dividido ${ }^{4}$ em outubro de 1977 sem qualquer consulta às duas populações interessadas. Desse ato arbitrário foi criada uma nova unidade federativa denominada Mato Grosso do Sul, tendo por capital a cidade de Campo Grande. Até então, essa região contava com a Universidade Estadual

\footnotetext{
${ }^{3}$ Empregamos o termo estado para designar as unidades federativas brasileiras e o termo Estado para referir-nos ao aparelho político-administrativo.

${ }^{4} \mathrm{O}$ termo histórico correto, consagrado pela historiografia e pelos documentos da ditadura militar é divisão e não desmembramento, por isso esse é o termo usado em nosso artigo.
} 
de Mato Grosso (UEMT) ${ }^{5}$, a qual, em 1979, foi federalizada passando a denominar-se Universidade Federal de Mato Grosso do Sul (UFMS).

A reestruturação administrativa da Instituição, necessidade decorrente da federalização, coincidiu, de certo modo, com a ampliação da luta social por democracia e justiça social na década de 1980. A federalização da UFMS impôs importantes modificações na conduta administrativa até então vigente. De um lado, houve a necessidade de adequação na forma de contratação de pessoal com o estabelecimento de planos de carreira e, por outro lado, a Instituição passou a compor o sistema de universidades federais do país, o que possibilitou aumentar e melhorar consideravelmente suas receitas orçamentárias e ampliar significativamente a quantidade de vagas ofertadas na Educação Superior do estado. Novos cursos foram criados e, na sede da Universidade, em Campo Grande, alguns cursos de Licenciatura, entre eles o de Matemática, foram implantados.

Estudo elaborado por comissão do Conselho Universitário identificou, ainda no processo de federalização, preocupação com a produção científica e com a titulação acadêmica. Segundo esse estudo, um aspecto:

[...] importante da federalização da UEMT foi a mudança do referencial de produção acadêmica. A UEMT tinha apenas a si própria como modelo, como parâmetro de funcionamento e critério de produtividade, pois dada as suas características não tinha congênere. A transformação em Instituição subordinada ao Governo Federal lançou a antiga UEMT num quadro de concorrência com outras universidades. Deste modo, um novo referencial de produção acadêmica se impôs, tais como: a questão da titulação do corpo docente, a produção científica (artigos, livros, etc.) e a necessidade da avaliação institucional. (UFMS, 1998, p.10)

A divisão de Mato Grosso e a criação de Mato Grosso do Sul acirraram a disputa entre as classes dirigentes sulistas pela condução política e burocrática do Estado ${ }^{6}$. Este fato teve como consequência, internamente à Instituição, novas repercussões na forma de composição do poder. $\mathrm{Na}$ antiga UEMT, o controle administrativo da instituição era construído internamente por acordos entre os grupos dominantes em cada campus e referendados pelo governador. Deste modo é que foi possível estabelecer seu alinhamento à política educacional da ditadura militar. Após a federalização, a forma de escolha dos dirigentes continuou sofrendo ingerências externas.

\footnotetext{
5 A UEMT foi criada pela Lei Estadual $n^{\circ}$ 2.947, de 16.09.1969. Sua origem data de 1962 com a criação da Faculdade de Farmácia e Odontologia de Campo Grande.

${ }^{6}$ Uma compreensão mais completa desse problema encontra-se em BITTAR, 1998.
} 
Entretanto, decorrente do processo de abertura política na década de 1980, por pressão da comunidade universitária, esse processo passou a ser feito por consulta a essa comunidade. Assim, no ano de 1985 houve a primeira consulta interna para a eleição de reitor e foi nesse cenário político que nasceu e se desenvolveu a Licenciatura em Matemática na UFMS.

A reestruturação dos Cursos de Licenciatura, na UFMS, ocorreu em um contexto marcado, de um lado, pela ausência de uma política institucional para os mesmos, e, de outro, influenciada pelo movimento nacional contestador às Licenciaturas Curtas. A Licenciatura na Instituição, não diferentemente do que acontecia na maior parte das Instituições de Ensino Superior (IES), parece ter sido entendida como curso de menor prestígio, com menos investimento por parte da mesma, geralmente oferecida em turno noturnos, frequentada por aqueles que trabalhavam de dia e estudavam a noite ${ }^{7}$. Apesar disso, os Cursos de Licenciatura passaram a incorporar muitas orientações das entidades científicas e congressos de educadores para se reestruturarem. Como consequência, uma primeira medida foi a extinção, na década de 1980, em quase todos os câmpus da UFMS, das Licenciaturas Curtas. Assim, passamos do modelo das Licenciaturas Curtas e das Parceladas, para o modelo da Licenciatura Plena.

A seguir analisamos a mudança no direcionamento dado à organização da Licenciatura, na década de 1980, como decorrência do processo de nascimento da UFMS. Para tanto procedemos à avaliação de sua reestruturação no contexto do debate nacional dessa época e à análise dos rumos da Licenciatura na Instituição nos anos de 1990. Em seguida, discutimos a transformação ocorrida nos cursos de Licenciaturas em Matemática, e finalizamos com uma análise da Licenciatura oferecida na capital, Campo Grande.

\section{Recusa à Licenciatura Curta: busca de novos caminhos}

A implantação da chamada Licenciatura Curta no Brasil ocorreu com a Lei no 5692/1971 e foi cercada de muita controvérsia. Pode-se mesmo afirmar que esse modelo de formação do professor sempre contou com a oposição dos professores militantes nas diversas entidades

\footnotetext{
7 "Introduzindo como alternativa aos cursos de pedagogia e licenciatura os institutos superiores de educação e as Escolas Normais Superiores, a LDB sinalizou para uma política educacional tendente a efetuar um nivelamento por baixo: os institutos superiores de educação emergem como instituições de nível superior de segunda categoria, provendo uma formação mais aligeirada, mais barata, por meio de cursos de curta duração." (SAVIANI, 2009, p.148)
} 
científicas, bem como daqueles que trabalhavam em boa parte das instituições de Ensino Superior, especialmente as IES públicas. Do ponto de vista da legislação, preconizava-se com estas Licenciaturas: propiciar a formação de maior contingente de professores em curto espaço de tempo, sobretudo para as regiões mais carentes do país; a instituição do ensino de ciências por projetos; o desenvolvimento, nos futuros professores, de atitudes científicas, mais do que o conhecimento aprofundado de conceitos de áreas específicas da ciência. Estes eram os objetivos explícitos dos idealizadores dessa modalidade de habilitação de professores. Porém, a intenção era a de formar um grande contingente de professores para substituir o chamado professor leigo, abundantemente atuando nas escolas públicas. "A perspectiva era a do mínimo por menos, isto é, o mínimo de qualificação necessária ao exercício da atividade docente pelo menor custo e tempo possíveis. Nesta perspectiva mais valeria uma formação aligeirada do que formação alguma." (NASCIMENTO, 2012, p.341)

A partir do ano de 1981 vários grupos de estudo foram formados tanto pelo Ministério da Educação (MEC), as chamadas Comissões de Especialistas, como pelas entidades científicas ${ }^{8}$. Inicialmente, vale destacar os pontos de discordância com relação à política de formação de professores de Ciências, apresentados em documento no ano de 1981 pela Sociedade Brasileira para o Progresso da Ciência (SBPC, 1981). Segundo o documento, o caráter abrangente do currículo, em contraposição ao curto espaço de tempo para seu desenvolvimento, inviabilizava a formação científica e pedagógica de professores para atuarem no Ensino de $1^{\circ}$ e $2^{\circ}$ graus, pois havia um descompasso entre a abrangência do currículo e o tempo disponível para sua execução.

Outra questão, não menos importante, referia-se à concepção de integração da ciência e o seu ensino por meio do método de projetos.

Esses dois temas são em conjunto a 'pedra de toque' da concepção de licenciatura expressa pela Resolução 30. A idéia do ensino de ciência integrada, em especial quando esse ensino toma a forma metodológica de realização de projetos, é vista como justificativa profunda da opção legal pela licenciatura polivalente; profunda porque responderia simultaneamente a imperativos epistemológicos, psicológicos e didáticos. (SBPC, 1981, p. 371).

\footnotetext{
${ }^{8}$ Apesar de algumas sociedades científicas, como a de Física e de Matemática, terem participado ativamente das discussões acerca da formação de professores, nesse artigo consideramos como referência documento publicado pela SPBC tanto pelo fato de ele congregar as principais propostas e reflexões das sociedade científicas como por essa ser, à época, uma sociedade de grande força política. Vale lembrar que a SBPC foi a primeira sociedade científica a se opor à ditadura militar e a apoiar as lutas democráticas da época.
} 
Ainda de acordo com o documento, dessa perspectiva decorria que muitas questões sobre o desenvolvimento da ciência e sua transposição didática acabavam, propositadamente ou não, interligadas.

1) a 'ciência' é uma só e deve-se estimular a integração das várias áreas especializadas; 2) o ensino de uma 'ciência integrada' no $1^{\circ}$ e $2^{\circ}$ graus da escola seria um estímulo a essa integração; 3) o ensino de ciência integrada no $1^{\circ}$ e $2^{\circ}$ graus equivaleria a um ensino integrado das ciências; 4) deve-se evitar tópicos abstratos ou formais no ensino de ciências; 5) deve-se explorar tópicos que despertem o interesse e o respeito pela ciência, isto é, tópicos ligados à vida diária, ao meio ambiente, à importância do momento; 6) deve-se privilegiar a aquisição de 'atitudes científicas' quando não for possível oferecer também o conteúdo aprofundado; 7) finalmente deve-se adotar o procedimento metodológico dos 'Projetos de Ciências' que englobaria na sala de aula a integração das ciências e a polivalência do professor (SBPC, 1981, p. 371).

A essas observações o documento contrapõe-se com os seguintes argumentos: quanto à “integração da ciência”, esta tentativa não encontra apoio no desenvolvimento histórico da mesma, o que pode ser observado pelo desenvolvimento de várias ciências especializadas unilateralmente. Porém, reconhece que isso não significa a impossibilidade de se estabelecer grupos de trabalho interdisciplinares, nem tampouco, o desconhecimento sobre o crescimento acelerado e, às vezes, estanque de muitas áreas do saber. Conclui que se não há uma "ciência integrada" como linha aberta e fecunda de pesquisas, muito menos se poderá propiciar seu surgimento por meio do ensino. Pelo contrário, não há justificativa para que se procure ensinar essa ilusão em qualquer grau de ensino (SBPC, 1981).

O documento da SBPC (1981, p.371) salienta ainda não ser "justificável a atitude dos defensores da licenciatura polivalente" como a única expressão representativa na formação de professores a se preocupar em evitar o formalismo no ensino de ciências e a incluir os problemas diários da vida no rol de conteúdos a serem trabalhados na escola. Na sequência, critica a proposta de separação entre a Licenciatura e o Bacharelado, preconizada pela legislação. Observa que este fato fez com que as universidades que optaram pelo oferecimento do Bacharelado se obrigassem a uma absurda duplicação de meios e esforços. Na contestação sobre a ideia de que esta legislação favorecia a formação de professores em larga escala e em curto espaço de tempo, constatou que, na realidade, o que se presenciou foi a proliferação desse tipo de curso nos estados em que esses argumentos se aplicavam com menor validade: São Paulo, Rio de Janeiro e Minas Gerais. Conclui afirmando que "[...] as licenciaturas curtas não foram aceitas como cursos 
adequados de formação profissional quer pelos estudantes, quer pelas instituições. Em muitos lugares se transformaram em bacharelados.” (SBPC, 1981, p. 373).

Neste documento da (SBPC, 1981) são apresentadas as propostas de uma Licenciatura para a formação do professor de Matemática, de Biologia, de Física e de Química. Sugeriu-se que o ensino de Matemática nos $1^{\circ}$ e $2^{\circ}$ graus fosse desenvolvido por meio de disciplina específica e ministrado por professores formados em Licenciatura Plena específica de Matemática. O ensino de Biologia, Química e Física, opcionalmente, poderia ser desenvolvido por disciplinas ${ }^{9}$ das $5^{\mathrm{a}}$ à $8^{\mathrm{a}}$ séries ou continuar organizado em um única disciplina denominada Ciências. Neste caso, os professores habilitados em Física, Química ou Biologia deveriam receber formação complementar para atuarem nesta disciplina. Quanto à formação pedagógica, propunha que o currículo contasse com disciplinas de História e Filosofia da Educação para permitirem, ao licenciado, compreender o caráter cultural e social da escola e da educação. Outra vertente do currículo cuidaria da formação do professor para atuação na sala de aula, reafirmando a importância de disciplinas como Prática de Ensino e Instrumentação para o Ensino. O documento preconizava, ainda, maior articulação entre a Licenciatura e o Bacharelado. Afirmava que o bacharel, ou bacharelando, de Física, Química ou Biologia, ao integralizar o mínimo necessário à Licenciatura e completar a formação para atuar na disciplina de Ciências, deveria receber, a qualquer tempo, o diploma correspondente.

Movimento semelhante ocorreu nas diferentes áreas, culminando, segundo Braga (1988), com um Encontro Nacional realizado em novembro de 1981 quando foi criada a Comissão Nacional dos Cursos de Formação do Educador, que concluiu:

a) em relação aos cursos de formação de educadores, as instituições deverão ter liberdade para propor e desenvolver experiências pedagógicas a partir de uma base comum nacional; b) a base comum nacional não deve ser concebida como um currículo mínimo ou um elenco de disciplinas, e sim como uma concepção básica de formação do educador e da definição de um corpo de conhecimentos fundamentais; c) todas as licenciaturas, inclusive a pedagogia, deverão ter esta base comum; d) define-se o educador como sendo aquele profissional 'que domina determinado conteúdo técnico, científico e pedagógico, que traduz o compromisso ético e político com os interesses da maioria da população brasileira e é capaz de perceber as relações existentes entre as atividades educacionais e a totalidade das relações sociais, econômicas, políticas e culturais em que o processo educacional ocorre, sendo capaz de atuar como agente de transformação da realidade em que se insere, assumindo, assim, seu compromisso histórico; e) os currículos de licenciatura, considerando a base comum nacional, devem incluir disciplinas relativas ao conteúdo específico e à formação pedagógica e disciplinas

\footnotetext{
${ }^{9}$ O documento salienta, todavia, que na opção do oferecimento do ensino de ciências por disciplinas - Física, Química e Biologia -, não significava que todas elas devessem estar presentes em todas as séries, mas, deveriam ser organizadas intercaladas e sequencialmente por série.
} 
integradoras; f) no que diz respeito à formação pedagógica, é necessário repensá-la, a partir da concepção do educador explicitada, tornando-a mais sólida e menos fragmentada, ampliar a carga horária e desenvolvê-la ao longo do curso; g) quanto às disciplinas integradoras devem ser centradas na análise da adequação, dosagem e organização do conhecimento a ser lecionado nos diversos graus de ensino e nas diferentes realidades; h) propõe-se a eliminação das licenciaturas curtas no prazo de três anos, bem como a extinção das licenciaturas parceladas e dos cursos de estudos sociais; i) advoga-se, nas instituições onde coexistam cursos de licenciaturas e bacharelado numa mesma área, que não exista separação inicial destes cursos, evitando-se a discriminação da licenciatura; j) defende-se um trabalho comum entre as unidades de educação e as demais unidades (BRAGA, 1988, p. 154).

Estas são as principais discussões que dominaram as propostas de reformulação das Licenciaturas na década de 1980. No entanto, apesar dos apelos veementes dos educadores, muitos dos problemas apontados não receberam a devida atenção, nem dos órgãos legisladores, nem das Universidades e Faculdades responsáveis pela formação de professores.

Em Mato Grosso do Sul, na década de 1980, a UFMS era a principal instituição responsável pela formação de professores. Sendo assim, analisamos, a seguir, a repercussão desse movimento na estruturação da Licenciatura na UFMS.

\section{A UFMS e sua Licenciatura}

Seguindo, ou não, as orientações advindas da comunidade científica na organização da Licenciatura decorrente dos debates desenvolvidos nos anos de 1980, a UFMS operou uma importante reestruturação desse curso. A federalização da Instituição, como já frisado, possibilitou, a partir de 1981, um processo importante de ampliação na oferta de vagas na Educação Superior em Mato Grosso do Sul. Assim, muitos cursos novos foram criados. O primeiro passo significativo foi o abandono das Licenciaturas Curtas ${ }^{10}$. Com vistas a se ter um panorama geral sobre os cursos implantados naquela década, apresentamos o Quadro 1.

\begin{tabular}{|l|l|c|}
\hline \multicolumn{1}{|c|}{ Curso } & \multicolumn{1}{c|}{ Cidade sede } & Ano de criação \\
\hline Administração & Campo Grande & 1981 \\
\hline Ciências Biológicas( L.P.) & Campo Grande & 1981 \\
\hline Educação Artística (L.P.) & Campo Grande & 1981 \\
\hline Física (L.P.) & Campo Grande & 1981 \\
\hline Matemática (L.P.) & Campo Grande & 1981 \\
\hline Pedagogia (L.P.) & Campo Grande & 1981 \\
\hline Química (L.P.) & Campo Grande & 1981 \\
\hline Geografia(L.P.) & Aquidauana & 1983 \\
\hline
\end{tabular}

${ }^{10}$ Somente o curso de Ciências, do campus de Aquidauana, não foi extinto na década de 1980, o que aconteceu em 1996. 


\begin{tabular}{|l|l|c|}
\hline Geografia (L.P.) & Dourados & 1983 \\
\hline História (L.P.) & Aquidauana & 1983 \\
\hline Ciências Biológicas (L.P.) & Corumbá & 1986 \\
\hline Ciências Biológicas (L.P.) & Três Lagoas & 1986 \\
\hline Geografia (L.P.) & Corumbá & 1986 \\
\hline Matemática (L.P.) & Corumbá & 1986 \\
\hline Matemática (L.P.) & Três Lagoas & 1986 \\
\hline Ciências da Computação & Campo Grande & 1987 \\
\hline Matemática (L.P.) & Dourados & 1987 \\
\hline Letras (L.P.) & Campo Grande & 1988 \\
\hline Comunicação Social & Campo Grande & 1989 \\
\hline
\end{tabular}

Quadro 1- Cursos criados pela UFMS na década de 1980

Fonte: Manual do acadêmico da UFMS, edição de 1997.

De um total de vinte (20) cursos criados no período de 1981 a 1990, dezesseis (16) são de Licenciatura, dos quais sete (7) foram implantados no campus de Campo Grande. Podemos inferir que aquela foi a década da Licenciatura na Instituição, pelo menos no que diz respeito à sua ampliação. Esse fenômeno, ao que tudo indica, está relacionado ao aumento do número de professores contratados para ministrar disciplinas de Matemática, Física, Biologia e Química em cursos como Engenharia, Medicina e Farmácia. Na sequência dessa tendência, a contratação de professores da área de Letras para ministrar aulas de Comunicação e Expressão em diferentes cursos, na capital, possibilitou a implantação do curso de Letras. Da mesma forma, a contratação de professores de Matemática e Biologia para os cursos de Ciências possibilitou a abertura das Licenciaturas em Matemática e Biologia em todos os campus da Universidade. Os cursos de Licenciatura foram, assim, influenciados, de forma significativa, pela ideia de que a formação de bons profissionais para atuarem na Educação Básica dependia apenas de uma forte formação na área específica, característica essa predominante na maioria dos currículos dos cursos implantados nesse período. Como fator agravante, constatamos ainda, a ausência de uma política de integração entre a Universidade e as escolas dos Ensinos Fundamental e Médio. Neste aspecto, predominava a tendência de reservar a disciplina Prática de Ensino para o último ano dos cursos.

Nessa década se, de um lado, houve o fator positivo do abandono das Licenciaturas Curtas, de outro, não se questionou a legislação que passou a orientar a formação de professores, sobretudo aquela relativa à normatização das habilitações específicas com vistas ao exercício da profissão. Assim, a ênfase dos documentos institucionais referentes à formação de professores passou a ser a legislação que buscava regulamentar a profissão docente. Nesse sentido, vamos encontrar ainda mais preocupação em atender a legislação que em observar o perfil do 
profissional a ser formado. Desse modo, os objetivos do Curso de Licenciatura passaram a ser determinados em função das habilitações que a legislação possibilitava oferecer.

\section{A formação do professor de Matemática: um novo momento}

A formação do professor de Matemática na UFMS, nos anos de 1980, passou a ser desenvolvida nos cursos de Licenciatura Plena. Nesse sentido, apresentamos aqui uma questão um tanto contraditória. Talvez fosse natural esperar que uma vez abandonados os cursos de Licenciatura Curta, no início daquela década, a formação de professores fosse ganhar um nível de atenção diferenciado. Entretanto, analisando os documentos da UFMS, percebemos que, em termos das proclamações institucionais, essa formação não estava reservada apenas às Licenciaturas específicas: ela era realizada nos mais diferentes cursos. Para compreendermos melhor essa afirmação, especialmente no que diz respeito à formação do professor de Matemática, elaboramos o Quadro 2 apoiados no Manual do Acadêmico publicado pela UFMS, que contém os cursos e habilitações, seus objetivos, a cidade onde funcionavam e a profissão para a qual cada curso habilitava. Os dados contidos nesse Quadro evidenciam claramente o fato de que não havia um direcionamento e uma especificidade na formação do professor, na Instituição. Além disso, o objetivo institucional anunciado é de que, de algum modo, a formação do professor de Matemática não era realizada somente no curso de Matemática, mas também nos cursos de Química, Física e até mesmo no de Ciências Biológicas ${ }^{11}$, no campus de Aquidauana. Outra questão não menos importante é o anúncio de que o curso de Matemática habilitava também professores de Física para atuarem no segundo grau.

\begin{tabular}{|c|c|c|c|c|}
\hline Curso & Cidade & Hab. & Objetivos & Profissão \\
\hline $\begin{array}{c}\text { FI } \\
\text { SI } \\
\text { CA }\end{array}$ & Campo Grande & Licenciatura $^{12}$ & $\begin{array}{l}\text { Formar professor de } 2^{\circ} \text { grau com } \\
\text { possibilidades de prosseguir na carreira } \\
\text { acadêmica como pesquisador. } \\
\text { Formar pesquisadores aptos a desenvolver } \\
\text { ciência e tecnologia, ou ainda a }\end{array}$ & $\begin{array}{l}\text { Professor de Física, } \\
\text { Química no } 2^{\circ} \text { grau e } \\
\text { Matemática no } 1^{\circ} \text { e } 2^{\circ} \\
\text { graus. }\end{array}$ \\
\hline
\end{tabular}

\footnotetext{
${ }^{11}$ Do ponto de vista legal o Manual do Acadêmico em suas edições dos anos de 1997 e 1998 produziu um equívoco. Nestas edições anuncia-se o curso de Licenciatura de $1^{\circ}$ grau em Ciências, com a Habilitação Plena em Biologia como um único curso, o de Ciências Biológicas. Pela legislação em vigor o que de fato havia eram dois cursos, sendo que para a Habilitação Plena em Biologia o candidato necessitava ter concluído antes o curso de Ciências Habilitação de $1^{\circ}$ grau. Outra questão não menos importante refere-se à confusão constante nestas edições do Manual a respeito do termo Licenciatura. Ele foi usado para classificar o curso de Ciências (Habilitação de $1^{\circ}$ grau), de Aquidauana, e também para designar cursos de Licenciatura Plena.

${ }^{12}$ No Manual do Acadêmico há referência apenas à Licenciatura, sem especificar se é Plena ou Curta.
} 


\begin{tabular}{|c|c|c|c|c|}
\hline & & & desenvolverem atividades técnicas. & Bacharel em Física. \\
\hline $\begin{array}{l}\text { MA } \\
\text { TE } \\
\text { MÁ } \\
\text { TI } \\
\text { CA }\end{array}$ & $\begin{array}{l}\text { Campo Grande, } \\
\text { Dourados, } \\
\text { Corumbá, Três } \\
\text { Lagoas, } \\
\text { Aquidauana } \\
\end{array}$ & Licenciatura & $\begin{array}{l}\text { Formar professores de Matemática, } \\
\text { Desenho Geométrico e de Física, para o } \\
\text { Magistério de } 1^{\circ} \text { e } 2^{\circ} \text { graus. Colaborar para } \\
\text { o desenvolvimento e formação integral do } \\
\text { educando. }\end{array}$ & $\begin{array}{l}\text { Professor de } \\
\text { Matemática e Desenho } \\
\text { Geométrico no } 1^{\circ} \text { e } 2^{\circ} \\
\text { graus e de Física no } 2^{\circ} \\
\text { grau }\end{array}$ \\
\hline $\begin{array}{l}\text { QUÍ } \\
\text { MI } \\
\text { CA }\end{array}$ & Campo Grande & $\begin{array}{l}\text { Licenciatura } \\
\text { Bacharelado }\end{array}$ & $\begin{array}{l}\text { Formar profissionais capazes de exercer } \\
\text { funções no Magistério de } 1^{\circ} \text { e } 2^{\circ} \text { graus, em } \\
\text { pesquisa na área de Química, contribuindo } \\
\text { para a formação integral dos educandos de } \\
1^{\circ} \text { e } 2^{\circ} \text { graus. } \\
\text { Formar profissionais capazes de exercer } \\
\text { funções de administração e assumir } \\
\text { responsabilidades técnicas em perícia, } \\
\text { consultoria, controle de qualidade, pesquisa } \\
\text { e desenvolvimento de métodos e produtos. }\end{array}$ & $\begin{array}{l}\text { Professor de } \\
\text { Matemática no } 1^{\circ} \\
\text { Grau, Física e } \\
\text { Química no } 2^{\circ} \text { grau } \\
\text { Químico. }\end{array}$ \\
\hline $\begin{array}{l}\text { CIENN } \\
\text { CIAS } \\
\text { BIO } \\
\text { LÓ } \\
\text { GI } \\
\text { CAS }\end{array}$ & Aquidauana & \begin{tabular}{|l} 
Licenciatura \\
Curta (LC) \\
Licenciatura \\
Plena (LP)
\end{tabular} & $\begin{array}{l}\text { Formar professores para o ensino de } \\
\text { Ciências de } 1^{\circ} \text { grau (LC) e de } 2^{\circ} \text { grau (LP), } \\
\text { fornecendo-lhes uma visão global não só da } \\
\text { ciência na vida cotidiana, mas também da } \\
\text { instrumentalização e recursos para a } \\
\text { programação do curso de } 1^{\circ} \text { e } 2^{\circ} \text { graus. } \\
\text { Colaborar para o desenvolvimento e } \\
\text { formação integral do educando } \\
\text { Preparar profissionais para atuarem nos } \\
\text { vários setores da Biologia. }\end{array}$ & $\begin{array}{l}\text { (LP)Professor de } \\
\text { Biologia no } 2^{\circ} \text { grau, } \\
\text { Biólogo (amparado } \\
\text { pela Lei } n^{\circ} 6.684 \text { de } \\
03 / 09 / 79)^{13} .\end{array}$ \\
\hline $\begin{array}{c}\mathrm{FI} \\
\mathrm{SI} \\
\mathrm{CA}^{14}\end{array}$ & Dourados & $\begin{array}{l}\text { Licenciatura } \\
\text { Plena }\end{array}$ & $\begin{array}{l}\text { Formar professor de } 2^{\circ} \text { grau com } \\
\text { possibilidades de prosseguir na carreira } \\
\text { acadêmica como pesquisador. }\end{array}$ & $\begin{array}{l}\text { Professor de Física, } \\
\text { Química no } 2^{\circ} \text { grau e } \\
\text { Matemática no } 1^{\circ} \text { e } 2^{\circ} \\
\text { graus e Bacharel em } \\
\text { Física. }\end{array}$ \\
\hline
\end{tabular}

Quadro 2 - Licenciaturas na UFMS em 1998

Fonte: Manual do Acadêmico UFMS, edição 1998.

Pode-se observar ainda que a formação do professor de Matemática nos diferentes campus da Instituição acabou configurada por uma mesma estrutura curricular ${ }^{15}$. Este fato, no caso específico dessa área de conhecimento, acabou gerando uma série de conflitos entre os diversos grupos responsáveis pela coordenação das atividades acadêmicas no interior dos cursos, devido à constituição do corpo docente de cada um deles. Tais conflitos não são encontrados em

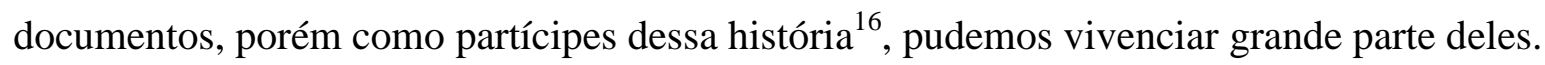

\footnotetext{
${ }^{13}$ No Manual de Acadêmico de 1998, não há referência à habilitação conferida pela Licenciatura Curta. Porém, no Manual de 1997, consta: formar "professores de Ciências Físicas, Biológicas e Matemática no $1^{\circ}$ grau”.

${ }^{14}$ Apesar de constar do Manual do Acadêmico, edição de 1998, com implantação para o primeiro semestre do ano letivo, esse curso não foi efetivamente implantado.

${ }^{15}$ Esse é um problema muito mais geral. Todos os cursos homônimos da instituição tinham que seguir os mesmos objetivos definidos na estrutura curricular única para todos.

${ }^{16}$ A primeira autora deste texto ingressou na Licenciatura em Matemática, Campo Grande, em 1981, e o segundo autor em 1983. Após a conclusão do curso e alguns anos em outras instituições, para estudos e/ou trabalho, retornaram à casa, como professores permanentes, em 1991 e em 1989, respectivamente.
} 
Do ponto de vista deste artigo, o interesse recaiu na análise específica sobre a formação profissional oferecida nos cursos de Licenciatura Plena em Matemática, principalmente pelo fato de que, apesar de a legislação da UFMS possibilitar a formação de professores de Matemática em outros cursos, na prática ela aconteceu de forma pouco significativa.

\section{A formação do professor de Matemática nos cursos de Licenciatura Plena em Matemática da UFMS}

De certo modo, os cursos de Licenciatura em Matemática da UFMS são desdobramentos das antigas Licenciaturas em Ciências, organizadas sob a égide da Resolução $30^{17}$ do Conselho Federal de Educação. O curso de Matemática do Centro Universitário de Corumbá foi implantado no ano de 1970 como habilitação dentro do curso de Ciências. No ano de 1986, o curso de Ciências foi extinto e o de Matemática passou a funcionar como Licenciatura Plena autorizado pela Resolução $\mathrm{n}^{\circ}$ 18/86 do Conselho Universitário e reconhecido pela portaria do MEC de $\mathrm{n}^{\circ}$ 2.372/91. O curso de Matemática de Campo Grande foi implantado no ano de 1981 tendo sido reconhecido pela portaria ministerial $n^{\circ} 158 / 84$ do MEC. Nessa época, a estrutura curricular dos cursos de Matemática era a mesma em todos os câmpus: Três Lagoas, Dourados ${ }^{18}$, Corumbá e Aquidauana. Em 2012, a UFMS contava com seis (06) Cursos de Licenciatura em Matemática na modalidade presencial e um na modalidade a distância, atendendo a diversas cidades do estado. Os cursos adquiriram autonomia e não tinham mais a mesma estrutura curricular. Essas mudanças visaram a atender as especificidades do corpo docente de cada campus e as particularidades de cada cidade e microrregião atendidas pelos cursos. O objetivo das Licenciaturas sempre foi atender a demanda de professores de Matemática, entretanto, a quantidade de formados ao longo dos anos não tem conseguido suprir o quantitativo necessário. Nesse sentido, na próxima parte deste artigo discutimos um desses cursos com mais detalhes, verificando as mudanças curriculares ocorridas ao longo de sua existência e a quantidade de egressos em trinta (30) anos.

\footnotetext{
${ }^{17}$ A Resolução no 30/74 (CFE, 1974) unificou as Licenciaturas das Ciências Físicas e Biológicas e de Matemática transformando-as na Licenciatura em Ciências com habilitação específica para o $1^{\circ}$ grau ou para o $1^{\circ}$ e $2^{\circ}$ graus.

${ }^{18}$ Em 2005, o câmpus de Dourados ganhou autonomia com o desmembramento da UFMS e a criação da Universidade Federal da Grande Dourados (UFGD).
} 


\section{A Licenciatura em Matemática no campus de Campo Grande: 30 anos de curso}

A Licenciatura em Matemática no campus de Campo Grande foi implantada em 1981 com uma estrutura curricular que lembrava o modelo de formação em Ciências com habilitação em Matemática: no primeiro ano do curso havia as disciplinas de Biologia e de Química, cada uma com sessenta (60) horas. Além disso, Física contava com duzentos e cinquenta horas (250) de aula teórica e noventa (90) de laboratório. Porém, essa estrutura foi alterada ainda no decorrer do primeiro ano de implantação da Licenciatura, sendo retiradas da matriz curricular as disciplinas de Biologia e de Química fazendo com que o curso passasse a ter as características de uma Licenciatura Plena em Matemática.

Em pesquisa realizada com egressos do referido curso (BITTAR et al, 2012) verificou-se que ao longo de trinta (30) anos aproximadamente mil e quatrocentos (1400) alunos ingressaram no curso, porém apenas duzentos e setenta e três (273) conseguiram concluí-lo, o que corresponde a 19,5\% de egressos. Esses são dados aproximativos, pois, por vezes, há ingressantes sendo contados em dobro, uma vez que alguns licenciandos prestam vestibular novamente passando a contar como novo aluno. Isso ocorre para limpar o histórico escolar de reprovações, que são, em geral, numerosas, e para ganhar mais tempo para a integralização das disciplinas e conclusão do curso. Esses dados corroboram com aqueles encontrados por Gatti (2011), de acordo com os quais a evasão em cursos de Licenciatura no país atingia o total de 70\%, ou seja, apenas cerca de $30 \%$ dos ingressantes conseguiam concluir o curso. Nas Licenciaturas em Matemática (no Brasil) esse dado é mais preocupante, chegando a somente $6,2 \%$ de egressos (GATTI, 1997).

Esses dados são preocupantes por duas razões: a primeira delas é o fato de esse total de egressos não dar conta de suprir a necessidade da sociedade e a segunda é o fato de as instituições manterem um curso em funcionamento com tão baixo índice de aproveitamento - especialmente quando se fala em universidade pública. (BITTAR et al., 2012)

Além da pouca quantidade de egressos, muitos deles não atuam na Educação Básica, ingressando na Educação Superior ou atuando em profissões sem relação com a educação, o que torna o quadro ainda mais drástico. Por isso, para tentar compreender minimamente a evasão no curso quanto às escolhas dos egressos, propusemo-nos a estudar os trinta anos de curso da Licenciatura em Matemática, campus de Campo Grande. 
Dentre o total de egressos (273), obtivemos dados de cento e sessenta e quatro (164) licenciados. Conseguimos entrar em contato direto com sessenta e dois (62), que responderam a um questionário elaborado visando a conhecer suas intenções ao ingressar no curso, sua atuação profissional e impressões acerca do curso frequentado e da profissão escolhida. Para obter dados sobre a atuação de uma quantidade maior de egressos recorremos a ex-professores e/ou colegas de ex-alunos que têm contato com eles, sabendo onde estão e onde atuam. Dessa forma, conseguimos dados de mais cento e dois (102) egressos, perfazendo o total de cento e sessenta e quatro (164) egressos, o que corresponde a aproximadamente 60\% do total de licenciados. Desse total, cento e vinte e três (123) atuam na Educação Básica, seja como técnicos nas secretarias de educação ou como professores de sala de aula; há ainda alguns, em menor quantidade, que atuam em cursinhos pré-vestibular ou na rede Kumon ${ }^{19}$. Uma vez que a maioria dos licenciados está atuando na Educação Básica poderia se concluir que o curso tem atingido seu objetivo maior, quer seja, formar professores para esse nível educacional, em especial para a escola pública. Entretanto, mesmo se considerarmos (hipoteticamente) que aproximadamente a mesma porcentagem dos professores formados com os quais não tivemos contato atua na Educação Básica, chega-se a um total de aproximadamente duzentos (200) egressos, em trinta (30) anos, atuando nesse setor educacional. Quantidade muito baixa considerando-se a necessidade de profissionais e o investimento feito ao longo de todos esses anos, além do total de ingressantes no curso - aproximadamente mil e quatrocentos (1400) - ao longo dos trinta (30) anos de sua existência.

Com as respostas ao questionário observamos que, do total de sessenta e dois (62) egressos, trinta e cinco (35) ingressaram no curso com intenção de atuar como professor, entretanto, desses, apenas onze (11) atuam na Educação Básica e quatro (4) na formação continuada vinculados ou não às Secretarias de Educação ou na rede Kumon. Isso significa que mais da metade atua no Ensino Superior ou em outras áreas sem qualquer ligação com a educação. Qual a razão para essa mudança ao longo do percurso? Alguns comentários feitos nos questionários fornecem pistas para essa questão, como é o caso da observação de Márcia ${ }^{20}$, professora da educação básica:

\footnotetext{
${ }^{19}$ Rede Kumon é uma instituição de ensino particular, originária no Japão, com diversas franquias no mundo. No Brasil oferece cursos de Português, Matemática, Japonês e Inglês. Atende a alunos de diversas idades e não se caracteriza como um ensino regular.

${ }^{20}$ Todos os nomes dos entrevistados são fictícios, conforme acordo estabelecido com os mesmos.
} 
Bom, todos nós sabemos que o curso de licenciatura não prepara alunos para atuar em sala propriamente dita, já soube de muitos casos de colegas que pediram exoneração do cargo por não saberem como lidar com os alunos, que por sua vez, estão se tornando apáticos, não aceitam a Matemática como disciplina. Já ouvi de alunos que Matemática deveria ser matéria optativa (MÁRCIA, 2013, grifo nosso).

Muitos egressos da Licenciatura em Matemática cursaram Mestrado imediatamente após a graduação, o que pode estar ligado ao perfil da Licenciatura, como indica a professora Ângela:

Uma pena que os cursos de licenciatura não preparem, de fato, os acadêmicos para atuarem como professores do ensino fundamental e médio, e os incentivem, sempre, a atuarem em carreiras paralelas ou ao Mestrado/Doutorado sem conhecer, de fato, os meandros da educação básica do país (ÂNGELA, 2013, grifo nosso).

Não devemos e nem queremos responsabilizar unicamente o curso pela escolha por outras profissões ou pela atuação na Educação Superior. As condições de trabalho e, sobretudo os salários de professores da Educação Básica são fatores que desencorajam a atuação nesse nível da educação dos poucos que conseguem concluir o curso, como explicita Pedro, professor na Educação Superior: “A baixa remuneração na educação básica me levou a preferir atuar na educação superior” (PEDRO, 2013). Essa situação não tende a mudar. De fato,

[...] se os salários continuarem pouco atrativos, se as condições de trabalho nas escolas não forem minimamente adequadas, se não for criado um suporte sociopedagógico no ambiente escolar, é possível que os docentes mais preparados tendam a evadir-se do magistério, a buscar outras oportunidades profissionais. (GATTI, 2011, p. 204)

Desse modo, cabe aqui uma reflexão acerca da quantidade de egressos e das escolhas realizadas. Uma vez que essa quantidade é muito baixa e que o egresso parece sair com perfil mais voltado à Educação Superior e que nesse setor há necessidade de professores, não haveria nada de anormal em suas escolhas. Onde está, então, o problema? O problema está na pouquíssima quantidade de egressos. Qual a razão para tamanha evasão de um curso de uma universidade pública? Para termos elementos que permitam compreender essa questão é preciso olhar para o Curso de Licenciatura em Matemática e buscar respostas para questões como: que curso é esse? Como ele se constitui? Por que razão, em trinta (30) anos apenas cerca de 20\% consegue concluí-lo? Será que dentre os $80 \%$ que evadiram não teria sido possível formar professores para a Educação Básica? Para buscar respostas a essas questões é preciso observar de 
perto o curso, e para tal analisamos as estruturas curriculares implantadas ao longo dos trinta (30) anos. A seguir fazemos um breve relato dos principais resultados encontrados ${ }^{21}$.

Ao longo desses 30 anos o Curso passou por vinte (20) modificações, algumas pouco significativas, como ajuste de carga horária ou nome de disciplina, e outras mais importantes, para atender demandas oficiais e/ou necessidades sentidas pelo corpo docente. A análise de todas as alterações realizadas evidenciou quatro mudanças mais importantes, realizadas em 1984, 1993, 2004 e 2011. Por esse motivo, analisamos, nesse texto, as matrizes curriculares vigentes em cada um desses anos e mais a de 1981, por ter sido a primeira do curso.

No que concerne à distribuição das disciplinas ao longo dos quatro (04) anos do curso, desde seu início, em 1981, até o ano de 2003, seguia-se o tradicional modelo 3+1, no qual as disciplinas ditas pedagógicas constavam somente no último ano de curso. Esse era o modelo padrão vigente nos cursos de Licenciatura em Matemática do país e que perdurou até recentemente, quando as diretrizes curriculares para as Licenciaturas lançaram uma nova proposta na qual desde o $1^{\circ}$ semestre de curso deve haver carga horária destinada à Prática de Ensino. Além disso, o Estágio Supervisionado teve aumento de carga horária, chegando, atualmente, ao total de quatrocentas (400) horas.

Para o estudo das estruturas curriculares utilizamos a Teoria da Base de Conhecimentos necessários para a docência (SHULMAN, 2001), buscando classificar cada disciplina em uma das sete categorias do conhecimento definidos por Shulman ${ }^{22}$ : Conhecimento do Conteúdo (Álgebra linear; Análise); Conhecimento Pedagógico Geral (Didática); Conhecimento dos Aprendizes e suas Categorias (Psicologia da Aprendizagem; Libras); Conhecimento do Conteúdo Pedagógico (Prática de Ensino, Estágios Supervisionados); Conhecimento de Contextos Educacionais (Estrutura e Funcionamento do $1^{\circ}$ e $2^{\circ}$ graus); Conhecimento sobre os Fins Educacionais (Estudos dos Problemas Brasileiros); Conhecimento do Currículo ${ }^{23}$. Os resultados obtidos foram tratados quantitativa e qualitativamente, como é necessário em uma pesquisa desse porte (GAMBOA, 1997).

Esse estudo foi realizado tanto para as disciplinas obrigatórias quanto para as optativas, entretanto, neste texto, apresentamos somente os resultados relativos às obrigatórias, uma vez que

\footnotetext{
${ }^{21} \mathrm{O}$ leitor interessado em detalhes dessa análise poderá encontra-los em (BITTAR; OLIVEIRA; FREITAS, 2013).

${ }^{22}$ Para ajudar o leitor a compreender cada uma dessas categorias, colocamos, entre parênteses, exemplos de disciplinas que permitem abordar, de modo especial o conhecimento focado na referida categoria.

${ }^{23}$ Nessa categoria podem ser consideradas disciplinas que tratam questões curriculares como diretrizes estaduais ou municipais e os Parâmetros Curriculares Nacionais.
} 
as optativas nem sempre eram oferecidas ${ }^{24}$ e são pouco representativas com relação às demais no que diz respeito à carga horária. Além disso, o perfil do curso é constituído essencialmente pelo conjunto das disciplinas obrigatórias. Na tabela 1 apresentamos os dados compilados da análise quantitativa.

Tabela 1: Porcentagem das categorias do conhecimento base nas matrizes curriculares estudadas

\begin{tabular}{cccccc}
\hline & $\mathbf{1 9 8 1}$ & $\mathbf{1 9 8 4}$ & $\mathbf{1 9 9 3}$ & $\mathbf{2 0 0 4}$ & $\mathbf{2 0 1 1}$ \\
\hline Conteúdo & $56,25 \%$ & $53,14 \%$ & $68,53 \%$ & $53,58 \%$ & $46,70 \%$ \\
\hline Pedagógico geral & $3,84 \%$ & $3,42 \%$ & $3,16 \%$ & $2,25 \%$ & $2,03 \%$ \\
Currículo & $0 \%$ & $0 \%$ & $0 \%$ & $0 \%$ & $0 \%$ \\
Aprendizes & $3,36 \%$ & $4 \%$ & $3,16 \%$ & $3,94 \%$ & $6,09 \%$ \\
Conteúdo pedagógico & $7,69 \%$ & $10,28 \%$ & $8,06 \%$ & $26,80 \%$ & $29,44 \%$ \\
Contextos educacionais & $2,88 \%$ & $3,42 \%$ & $3,16 \%$ & $2,25 \%$ & $2,03 \%$ \\
Fins educacionais & $1,92 \%$ & $2,28 \%$ & $0 \%$ & $0 \%$ & $0 \%$ \\
\hline Outros $^{\mathbf{2 5}}$ & $25,96 \%$ & $23,42 \%$ & $13,91 \%$ & $11,14 \%$ & $13,70 \%$ \\
\hline
\end{tabular}

Fonte: Bittar et al, 2013.

As principais observações que podem ser feitas são de que há, no Curso, ênfase em disciplinas relacionadas ao Conhecimento do Conteúdo, o que não representa uma surpresa tendo em vista outras pesquisas realizadas e a forte influência do modelo 3+1. Além disso, percebe-se, ao longo dos anos, a extinção de disciplinas sobre os fins educacionais. É também bastante significativa a ausência de disciplinas destinadas ao Conhecimento Curricular, que discutem o currículo e suas formas. Isso não significa que temas relacionados a currículo estejam totalmente ausentes do curso, pois podem ser inseridos em disciplinas como as de Prática de Ensino, entretanto, nesse caso, a ênfase não é a mesma que tal tema merece ter. Outro fato observado é a existência de disciplinas com objetivo de atender as diretrizes curriculares, especialmente as que entraram em vigor em 2001. Por fim, observa-se dicotomia entre as disciplinas de conteúdo matemático e as de conteúdo didático-pedagógico, como ocorre também, de modo geral, em outras Licenciaturas. De fato, Souza e Garnica (2004), em pesquisa com licenciandos em Matemática da Faculdade de Ciências da UNESP de Bauru, que tiveram formação prévia no curso de magistério do Centro de Formação e Aperfeiçoamento do Magistério (CEFAM) e em outra formação, antes de ingressar na Licenciatura em Matemática, observaram que:

\footnotetext{
${ }^{24}$ Não foi possível obter oficialmente essa informação, entretanto, nossa estreita relação com o Curso, inicialmente como alunos e posteriormente como professores, nos permite fazer tal afirmação.

${ }^{25}$ Em Outros constam disciplinas não classificadas nas categorias anteriormente apresentadas, como: Física, Educação Física, Ciência da Computação e Língua Portuguesa.
} 
Enquanto no CEFAM, segundo os depoentes, havia uma predominante valorização de conteúdos pedagógicos, na Licenciatura há, num processo histórico, uma espécie de 'divisão' entre estes e os conteúdos específicos de Matemática, na qual, de acordo com os depoentes, os últimos são tendencialmente mais valorizados. (SOUZA ; GARNICA, 2004, p. 37)

\section{Conclusão}

Nossa intenção neste artigo foi de levantar algumas questões na busca de compreensão para a formação de professores de Matemática em uma instituição de ensino pública ao longo de várias décadas. Cremos ser preciso entender o processo histórico da constituição do curso para obtermos elementos de resposta à questão da pouca quantidade de egressos do curso. Essa preocupação não está presente somente em nossos estudos.

[...] a questão da formação de professores constitui-se em um enorme desafio para as políticas educacionais, uma vez que a origem dessa formação deficitária está na expansão das redes de ensino em curto espaço de tempo e na conseqüente necessidade de ampliação do quadro docente, pois, de acordo com os estudos e avaliações disponíveis, a formação de professores não deu conta de prover o ensino com profissionais adequadamente qualificados. (OLIVEIRA, 2003, p.6)

Uma vez que a formação não tem sido condizente com as necessidades da sociedade, é preciso refletir sobre que profissional queremos e, para isso, deve-se considerar também as necessidades do professor no exercício da docência. Nossos estudos indicam que a formação inicial não tem dado conta dessa tarefa e isso desde sua implantação. Estudos e pesquisas apontam para a importância do rompimento do modelo $3+1$ que vigorou durante muitos anos. As Diretrizes Curriculares Nacionais para a Licenciatura, implantadas em 2001, assim preconizavam. Uma das principais razões dessa ruptura é a dicotomia existente, no modelo $3+1$, entre disciplinas de conteúdo e disciplinas pedagógicas. Cabe ao licenciando estabelecer conexões necessárias e úteis à sua profissão. Nesse sentido, essas Diretrizes também enfatizam a importância de o futuro professor ter contato com sua profissão desde sua entrada no Curso, por meio de disciplinas de Prática e que o Estágio Supervisionado comece na segunda metade do Curso. Uma breve leitura de uma estrutura curricular pode levar a crer que o desejado está sendo praticado, pois essas exigências parecem ser contempladas. Entretanto, uma análise mais detalhada mostra que muito há para ser feito, a começar pelo formador de professores, pois não basta colocar disciplinas de Prática desde o início do Curso. É necessário pensar o quê e como isso deve ser feito e como deve ser trabalhado e articulado todo o conjunto de disciplinas e outras 
atividades da Licenciatura. A história mostra que desde as primeiras Licenciaturas, na UFMS, até as atuais, diversas mudanças foram realizadas; desde mudanças profundas nos modelos de formação, como Licenciatura Curta ou Plena, a mudanças nas estruturas curriculares, mas, infelizmente, ainda estamos buscando caminhos para a formação de um profissional que possa atuar na Educação Básica com os alunos e condições que temos.

Cabe, por fim, observar que, ao buscarmos relações entre a quantidade de egressos do Curso e sua estrutura, constatamos que a maior quantidade de formados dentro do período de quatro anos, ocorreu com aqueles que ingressaram em 2004, cuja estrutura parecia - ao menos em intenção - efetivamente levar em consideração as orientações das Diretrizes Curriculares Nacionais para as Licenciaturas, inclusive articulando disciplinas de Conteúdo a questões didático-pedagógicas ${ }^{26}$. Entretanto, seriam precisos novos dados para comprovar tal hipótese o que, infelizmente, não é possível uma vez que tal estrutura foi novamente modificada, voltando, em nossa opinião, a algumas características semelhantes a estruturas anteriores. Além disso, a quantidade de egressos voltou a diminuir. Coincidência? Um dado para futuras reflexões.

\section{Referências}

BITTAR, M.; OLIVEIRA, A. B. de; FREITAS, J. L. M. de. Um estudo sobre mudanças curriculares em uma licenciatura em Matemática ao longo de 30 anos. HISTEDBR on-line, Campinas, v.13, n. 49, p. 294-308, mar. 2013.

BITTAR, M; OLIVEIRA, A. B. de; SANTOS, R. M.; BURIGATO, S. M. da S.. A Evasão em um Curso de Matemática em 30 anos. EM TEIA: Revista de Educação Matemática e Tecnológica

Iberoamericana, v. 3, n. 1, p. 1-16, 2012.

BITTAR, M. Estado, educação e transição democrática em Mato Grosso do Sul. Campo Grande: Editora UFMS. 1998.

BRAGA, M. M. A licenciatura no Brasil: um breve histórico sobre o período 1973-1987. Ciência e cultura, Sociedade Brasileira para o Progresso da Ciência, São Paulo, v.2, n. 40, p.16-27, fev. 1988.

GAMBOA, S. A. S. A dialética na pesquisa em educação: elementos de contexto. In: FAZENDA, I. (Org.). Metodologia da pesquisa educacional. São Paulo: Cortez, 1997. p. 91-116.

GATTI, B. A. Formação de professores e carreira: problemas e movimentos de renovação. Campinas, SP: Autores Associados, 1997. 135p.

GATTI, B. A. Políticas Docentes no Brasil: um estado da arte. Brasília: Ministério da Educação, 2011. 295p.

\footnotetext{
${ }^{26}$ Em artigo em preparação discutimos, em detalhes, a proposta da estrutura curricular implantada em 2004.
} 
NASCIMENTO, T. R. A criação das licenciaturas curtas no Brasil. HISTEDBR On-line, Campinas, v. 12, n.45, p. 340-346, mar. 2012.

OLIVEIRA, G. A. P. A Concepção de egressos de um curso de Pedagogia acerca da contribuição do trabalho de conclusão de curso. 2003. 136 f. Dissertação (Mestrado em Educação) - Faculdade de Educação, Universidade Estadual de Campinas (UNICAMP), Campinas, 2003.

RAGAZZINI, D. Para quem e o que testemunham as fontes da História da Educação? Educar em Revista, Curitiba, v. único, n. 18, p.13-28, set. 2001.

SAVIANI, D. Formação de professores: aspectos históricos e teóricos do problema no contexto brasileiro. In.: Revista Brasileira de Educação v. 14 n. 40, p.143-155, jan./abr. 2009.

SHULMAN, L. Knowledge and teaching: Foundations of the new reform. Harvard Educational Review, cidade, v. 57, n. 1 , p. 1-23, abr. 1987.

SBPC - Sugestões para formação de professores da área científica para as escolas de $1^{\circ}$ e $2^{\circ}$ graus. Ciência e Cultura, São Paulo, v. 1, n. 33, p. 369-377, mar. 1981.

SOUZA, L. A. de; GARNICA, A. V. M. Formação de professores de matemática: um estudo sobre a influência da formação pedagógica prévia em um curso de licenciatura. Ciência e Educação, Bauru, v. 10, n. 1, p. 23-39, 2004.

UNIVERSIDADE FEDERAL DE MATO GROSSO DO SUL. Manual do Acadêmico. Campo Grande: UFMS 1997. (mimeo).

UNIVERSIDADE FEDERAL DE MATO GROSSO DO SUL. Manual do Acadêmico. Campo Grande: UFMS 1998. (mimeo).

UNIVERSIDADE FEDERAL DE MATO GROSSO DO SUL. Estudos sobre evasão escolar e reorganização dos Cursos da UFMS. Campo Grande: UFMS 1998. (mimeo).

Submetido em Abril de 2014. Aprovado em Setembro de 2014. 